(C) 2019 IEEE. Personal use of this material is permitted. Permission from IEEE must be obtained for all other uses, in any current or future media, including reprinting/republishing this material for advertising or promotional purposes, creating new collective works, for resale or redistribution to servers or lists, or reuse of any copyrighted component of this work in other works. 


\title{
Operationalising Ambidexterity- The Role of "Better" Management Practices in High-Variety, Low-Volume Manufacturing
}

\author{
Katic, M. ${ }^{1}$, Cetindamar, D. ${ }^{1}$, Agarwal, R. ${ }^{2}$, and Sick, N. ${ }^{1}$ \\ ${ }^{1}$ School of Information, Systems and Modelling, Faculty of Engineering and Information Technology, University of Technology \\ Sydney (UTS), Sydney, Australia. \\ ${ }^{2}$ Management Discipline Group, UTS Business, Sydney, Australia.
}

\begin{abstract}
Innovation and change are fundamental to the long-term sustainability of any organisation. Whilst it is important to improve operating efficiency in the bid to become more cost competitive, there is still an underlying need to venture out of the norm and explore new opportunities. Though a great deal of research has emerged regarding the achievement of ambidexterity, there remains a gap in understanding how this is actually operationalised in organisations.

This paper takes aim at this problem in the context of SME manufacturers that produce a high variety of customised products at low volumes (HVLV). Under such circumstances, ambidexterity appears intuitively easier to achieve given the manufacturer is designed to be as flexible as possible in the first place - though, it would seem this may be to their detriment. Based on a literature review and drawing from ambidexterity and organisational theory, our contribution is geared towards investigating the underlying mechanisms that make HVLV manufacturers ambidextrous in the first place. In particular, we concern ourselves with exploring how ambidexterity is enacted through what are deemed "better" management practices that result in innovative organisations. By better understanding the more latent characteristics of HVLV manufacturers, we shed some light on the interactions between external and internal influences affecting the impact of ambidexterity under such an environment. Further theoretical and managerial implications are discussed.
\end{abstract}

\section{INTRODUCTION}

Ambidexterity has become a pervasive concept in organisation science, helping to explain key phenomena in areas including strategy and operations as well as organisational behaviour - and rightly so. The ability of an organisation to both exploit existing assets towards operational superiority and at the same time explore new opportunities towards future growth has proven to be a corner stone of longterm competitive advantage for organisations [1] - particularly those operating in highly dynamic environments [2]. Whilst much has been accomplished by way of understanding the concept and, for instance, the more narrow question of how organisations can achieve optimal structures to deal with the competing demands of innovation and operational efficiency, the broader question concerning how exactly ambidexterity can be achieved remains a pressing issue.

This paper presents a work-in-progress investigating the role of "better" management practices in operationalising ambidexterity in an organisational context known as HighVariety, Low-Volume (HVLV) manufacturing. HVLV manufacturers are quite unique in that the customisation-driven manufacturing strategy being adopted means dynamism impacts them from the inside as well as the outside, yet they seem to operate in a market that can be characterised as "stable". They are project-based, yet they dabble in repeat business. They also provide manufacturing services and yet seem to also rely on selling their own products. It would appear that, by definition, HVLV manufacturers are ambidextrous, indeed they have to be - the act of exploiting existing knowledge and exploring new opportunities is part of their daily business. The fact such organisations must portray some ambidextrous capabilities in not only contending with the exploration/exploitation paradox but also the multitude of other organisational tensions arising from their manufacturing strategy makes them an interesting candidate for further study.

Whilst some recent attempts have been made to understand the underlying "mechanisms" of ambidexterity in similar organisational contexts including, for instance, project-based organisations [c.f. 3], as well as the role of operations management in facilitating exploration and exploration towards greater manufacturing performance [4-6] there remains an untapped need to understand how ambidexterity is actually enacted in such organisational contexts.

We build on previous insights by taking a more nuanced approach underpinned by the routines-based view of competitive advantage and a paradox-based view of organisational tensions. We exemplify, how ambidexterity can be operationalised by the day-to-day management practices HVLV manufacturers actually undertake. In doing so, we also depart from the apparent efficiency-driven research paradigm in HVLV manufacturing towards a balanced understanding of how better management practices, typically characterised as "operational" routines, can help facilitate the simultaneous pursuit of exploration and exploitation.

The remainder of this paper is organised as follows: Section 2 provides an overview of ambidexterity as a concept, followed by Section 3 which reviews some recent work on the link between operations management practices and organisational ambidexterity. Section 4 introduces HVLV manufacturers as the context within which this paper places focus, key operational and strategic characteristics are discussed. Section 5 follows by providing an overview of 
better management practice theory and explicates the role of better management practices in the context of HVLV manufacturing. Section 6 brings the insights from ambidexterity and better management practices in the context of HVLV manufacturing together and, through the lens of the routines-based view of organisation and paradox-based view of organisational tensions, provides an introductory association between ambidexterity and its enactment as better management practices. We conclude this paper with potential managerial implications as well as areas of further research we intend to follow through with.

\section{AMBIDEXTERITY - AN OVERVIEW}

Ambidexterity typically refers to an organisations' ability to undertake both exploratory and exploitative activities at the same time [7]. This, of course, is based on the presumption that the exploration of new opportunities and exploitation of existing capabilities and resources are a fundamental component of sustainable competitive advantage [8]. Indeed, the tensions that ensue as part of an organisations' pursuit of operational excellence for today and innovation and change for tomorrow have (and continue to be) key areas of concern for academics and practitioners alike - particularly because one does not play well with the other, at least in the short-term.

Undertaking exploration requires fundamentally different structures, processes and culture than exploitation [1]. The difficulty for decision makers, in this instance, concerns building/buying or renting resources to undertake both. Investing in exploitation, for example, emphasises short-term gain, present-time survival and stability over long-term gain, survival for the future and change [9]. In his seminal article, March [10], although not explicitly referring to ambidexterity, recognised these inherent organisational tensions and brokefree from traditional thinking at the time to suggest that organisations can (and should) undertake both. Based on these perhaps more behavioural roots, two now well-established means to achieve ambidexterity emerged: structural and contextual ambidexterity.

The structural school of thought would emphasise an organisational design where different business units would undertake either exploratory or exploitative activities. In this instance, the key to achieving ambidexterity would rest on the ability of the top management team to maintain strategic alignment between the two seemingly disparate groups - some mechanisms of which can include effective dissemination of an organisational identity and value systems [1]. The contextual school, on the other hand, would suggests the ability of an organisation achieve ambidexterity rests at the individual/team level where the key is to "build an organisational context" that promotes behavioural orientation towards a combined capacity for both exploitation and exploration" [11]. Though both approaches have been criticised, the structural approach in being overly ambitious in resource constrained contexts [12] and the contextual approach in the difficulty associated with managerial cognition [13]. Contemporary thinking has also exemplified how the two approaches to achieve ambidexterity are not mutually exclusive in that both are essential components in an organisations ambidexterity journey $[11,14]$.
Other recent approaches in ambidexterity research recognise that the concept is still very much a function of strategic choice and that whilst it is indeed important to help managers "deal with" internal contradictions in relation to exploitation and exploration, choices still have to be made and those choices need to be in line with market requirements $[3,9$, 15]. D’Souza, Sigdyal [15], for example, proposed a "relative ambidexterity framework" which explicitly takes into consideration market forces in the decision to build either exploration or exploitation capabilities. In their work, they also recognise the importance of undertaking both exploration and exploitation activities to the long-term success of organisations, though they also recognise that the two are still very different constructs and not always complimentary. They also place concern over the fact that certain industries don't have to be as "ambidextrous" as others - based on the findings of Junni, Sarala [2].

\section{AMBIDEXTERITY AND OPERATIONS MANAGEMENT PRACTICES}

In the context of manufacturing, operational capabilities are said to be a more effective means to achieve the simultaneous pursuit of exploratory and exploitative innovations - if, indeed, it is even necessary. From a strategic perspective, Matthews, Tan [16], for instance, investigated the impact of process improvement initiatives on organisational ambidexterity in project-based organisations where they found the particular organisations competitive priorities guide the direction of focus on what they label as exploratory and/or exploitative learning. Based on case-study evidence, they observed that placing an ambidexterity lens on process-improvement initiatives within a project-based organisation shed light on how projects can observe both exploitative and exploratory learning. Taking it one step further Tamayo-Torres, Tamayo-Torres [17] demonstrated that ambidexterity is a pre-curser for, and enabler of, manufacturing performance improvements as they pertain to quality, speed, flexibility and cost. Based on their study of 231 Spanish manufacturing companies, they also found that higher environmental dynamism strengthened this effect and thus echoing the results of Frank, Güttel [18] where higher environmental dynamism increased the importance of ambidextrous capabilities. Others including Herzallah, Gutierrez-Gutierrez [19] linked what they labelled as "quality ambidexterity" to strategic intent - concluding that ambidextrous capabilities had a positive relationship on cost leadership, differentiation and focus organisational strategies (though focus had a negative relationship on manufacturing performance).

The classic debate of flexibility vs. stability in manufacturing organisational performance has also re-emerged in ambidexterity literature. This research stems from the notion that routines that act to increase efficiency and operational effectiveness (variation reducing routines) significantly weakens the ability of an organisation to reconfigure its existing resource base. 
A commentary piece by Adler, Benner [6] provides a good starting point for more recent perspectives on this debate. In their paper, the authors return to the issue of process management routines and their impact on exploratory and exploitative learning. Based on their experience, the authors reiterate that whilst process management (or best-practices) can be a source of innovation in the short term, once codified in the organisations' memory in the form of standards, procedures, documentation and other artefacts, the ability of an organisation to respond to major changes in the marketplace (or indeed, create them) diminishes significantly. This is provided credence in that some authors have recognised that different operational capabilities exist, all with a different area of focus (for instance, customisation, cooperation, innovation, improvement and so on)[20]. In that, operational capabilities can also potentially conflict with each other and ambidextrous capabilities can help facilitate their productive complementarity [4, 5]. Whilst there exists evidence that certain routines can help build exploratory and exploitative organisational capabilities, the evidence that they impact both, and how they actually aid in achieving ambidexterity remains mixed. Recent reviews by Wilden, Hohberger [21] and Turner, Swart [3] as well as commentary by Benner and Tushman [22] all recognise the need to need to understand the mechanisms enabling ambidexterity, given its conceptualisation as a dynamic capability.

\section{High-VARIETY, LOW-VOLUME MANUFACTURER CHARACTERISTICS}

High-Variety, Low-Volume manufacturers can be characterised as small to medium sized businesses (SME's) that produce a wide variety of customised products at lowvolumes. As far as manufacturing strategy is concerned, they are typically considered either Engineer to Order (ETO) and/or Make-to-Order (MTO) depending on where the customer order penetrates the manufacturing value chain. For instance, some HVLV manufacturers may primarily operate on the basis of producing products from pre-defined designs provided by their customers whilst others may provide turn-key solutions requiring extensive design activities - often from vague descriptions provided by their customers.

As one can imagine from this rather generic characterisation of HVLV manufacturing, coming up with an all-encompassing definition or typology proves to be quite a difficult exercise. For this reason, and in line with other studies concerning HVLV manufacturing [23, 24], we take into consideration SME manufacturers that exhibit both MTO and ETO characteristics. From this perspective, there are indeed some "peculiarities" that can be considered unique to HVLV manufacturers, particularly when it comes to strategic and operational characteristics [24]. The following briefly summarises some of these key characteristics.

From an operational perspective and stemming from the adoption of a customisation-based manufacturing strategy (and the many uncertainties associated with this), HVLV manufacturers are observed to have significant difficulty in developing plans (including sales, production and procurement plans) [25]. Based off the characterisation provided by Adrodegari, Bacchetti [25], Persona, Regattieri [26], Amaro,
Hendry [23] and Little, Rollins [27], forecasting is almost impossible, and the supplier relationships are practically nonexistent due to the nature of the demand driven manufacturing approach. In addition, the production system is designed specifically to cater for a high variety of products; therefore, the job-shop style of production is typically adopted. This means work routings are complex; general purpose machinery is adopted and setup times as well as WIP (work in progress) are also high.

From a strategic perspective, the competitive priorities and criteria are also unique to HVLV manufacturers. The orderwinners and order-qualifiers framework brought forward by Hill [28] (also adopted by [29] and [23]) suggests HVLV manufacturers typically compete on the basis of price, delivery time, delivery reliability, conformance to quality, "specialist" know-how and some unique production capabilities. Though, these have been known to change depending on the external market conditions of the time and the decision makers' perception of who their competitors are.

For example, a study by Amaro, Hendry [23] suggests firms which perceive their direct competitors as very similar organisations which adopt the same manufacturing strategy and production process would assume they compete on the basis of price, delivery time, capability and know-how. However, the same study also suggests firms who perceive their main competition to be mass-producers (or those which operate under a completely different manufacturing strategy) would also claim customisation to be a key area of competitive advantage (which is not evident in the previous example). Whilst one can identify the mechanisms used by HVLV manufacturers to gain competitive advantage, the importance (or the priority rank) of these mechanisms is debatable and remains to be an open discussion in HVLV literature. A particular driver for this is the notion that HVLV manufacturers who perceive price to be the most important criteria for winning an order seem to attach significant strategic importance to achieving repeat business [23]. This occurs from the significant difficulty of reducing costs based on a highvariety oriented manufacturing system. In this case, the degree to which repeat business presents a key strategic decision also seems to influence the weighting or precedence of competitive priorities [29]. The type of customer relationship pursued by HVLV manufacturers is also altered depending on the competitive priorities of these firms [30].

Though, this is not to say that a more foundational understanding of their strategic orientation cannot be deduced. Given the importance of strategy in the development (and adoption) of manufacturing capabilities and, hence, the importance for the discussions to follow in this paper, such an understanding becomes vital. This can be obtained by investigating HVLV manufacturers based on their strategic intent and what came to be known as "core characteristics". Core characteristics are said to be the "soul" or "essence" of an organisation [31], guiding management decisions as they endure throughout the lifetime of an organisation [32]. When viewed in this light two core characteristics (and by virtue, their strategic intent) can be identified in the strategic choice to emphasise customisation and the flexibility necessary to facilitate this. Indeed, when viewed in this light two main 
competitive priorities emerge - the ability to produce highly customised products and the organisational flexibility required to make that happen.

For instance, in a review of ETO supply chain strategies, Gosling and Naim [33] suggest flexibility and customisation (albeit using different terminology) can both be core characteristics and part of key improvement strategies of ETO organisations. Similarly Salvador, Rungtusanatham [34] in their study of strategic trade-offs within a Build to Order (BTO) organisation focussed on both volume flexibility and mix flexibility, proclaiming both to be core to BTO organisation success. In addition, earlier studies on HVLV organisational improvement focussed on leveraging their core capabilities to produce customised products through various order-control and release mechanisms [35, 36] as well as strategies to reduce the chasm between sales and engineering [37]. In such studies, flexibility appeared to be a given characteristic of HVLV organisations. This was, perhaps, assuming the manufacturing function can deal with a highvariety of products. The key was in managing the relationship between customers (both external and internal to the manufacturer) to ensure due-dates are set correctly (and adhered to) as well as the correct job was released at the correct time to ensure maximum resource utilisation whilst allowing room for problem solving. Following on from this stream, Zorzini, Stevenson [38] also identify customisation and flexibility (labelled as the location of the Customer Order Penetration Point and System Flexibility respectively) as key contingency factors in the success of customer enquiry management - ultimately resulting in improved organisational performance of HVLV organisations (labelled as non-make-tostock). As will become evident in the analysis to follow, an understanding of the context within which HVLV manufacturers operate becomes crucial to understanding the operations with which their manufacturing strategy, and by association, their ambidextrous capabilities stem from.

\section{Better Management Practices AND HVLV MANUFACTURING}

\section{A. An Overview of Better Management Practice Research}

Recent times have observed a deluge of large-scale empirical studies suggesting the existence of management practices that appear universally "better" than others. These studies claim the adoption of these so-called "structured" management practices is a key force in explaining differences in performance at the firm level [39], as well as explaining the differences in performance between entire economies [40, 41] and different industrial contexts as well $[42,43]$. In addition to all of this - and perhaps even inspired by the results of these large-scale empirical studies on "better" management practices - some have even articulated a "practice-based" theory of the firm $[44,45]$ seeking to explain the competitive advantage of organisations via the adoption of better management practices. This line of theorising, indeed, stems from the tradition of best practice research - of which operations management literature has a rich history in advocating [46]. Though, this is not to say there are not any important considerations in this line of reasoning.

Firstly, contingency theory plays a key role in the age-old argument where certain management practices are only effective in improving business performance within specific contexts $[47,48]$. Common examples of this include the use of Lean Manufacturing and other World Class Manufacturing techniques within organisations producing highly customised products at low volumes $[49,50]$. In this instance, there is a clear mismatch between marketing, manufacturing strategy and production processes if the management practices are adopted in their entirety - that is to say, these particular practices must be adapted to suit different operating environments.

Secondly, and perhaps a more recent argument, stems from the idea of "best "or "better" management practices as fashions or fads making their way into mainstream industries. The temporal nature of management practices as well as the relative immaturity of the management discipline (compared to other social sciences) often gives rise to questions concerning their credibility and validity [39, 51]. Again, evidence of poor organisational performance from the rapid adoption and diffusion of what seem to be "best practices" within a plethora of different industries appears to be a major driver of these concerns[52]. None-the-less Alexopoulos and Tombe [53] quantified the effects of managerial innovations on various US macro-economic performance measures and found a significant correlation between the rise in managerial innovations (including Management by Objectives and Quality Circles both of which considered to be fads [54]) and increases in macro-economic performance. In fact Alexopoulos and Tombe [53] and Bloom, Sadun [55] also suggest that managerial innovations are just as important (if not more so) as nonmanagerial innovation in explaining changes in output to measures including productivity. Other seminal benchmarking studies across various countries also suggest the existence of management practices which appear "better" at improving organisational performance than others $[56,57]$.

\section{B. Better Management Practices and HVLV Manufacturing}

Keeping in mind the unique HVLV manufacturing context as well as the caveats presented previously, there have been some attempts at explicating what can be deemed better management practices in HVLV manufacturing literature. Much of this work, however, appears to stem from an underlying need for HVLV manufacturers to effectively "deal with" the dynamic nature of their manufacturing strategy and the complexities associated with this approach [26 for a review of key barriers to HVLV manufacturing excellence, 27 , see 58 for a review of these factors, see also 59, 60]. In this instance, the World Class Manufacturing (WCM) and Lean manufacturing paradigms seem to prevail in the more comprehensive studies on HVLV better management practices $[50,61,62]$.

Though, this is not to say that the WCM or Lean approaches were adopted in the entirety. Hendry [50], in an early investigation of the applicability of WCM principles and 
measures to the HVLV manufacturing environment presented one such study. She found, for example, that companies explicitly choosing to retain a job-shop style layout (as HVLV manufacturers are inclined to do) typically rank poorly in existing WCM assessments as the cellular layout is the preferred "world-class" standard. Other principles including a major reduction in time to market was also found to conflict with basic HVLV manufacturing characteristics (as mentioned in a previous section, many HVLV manufacturers are primarily involved in build-to-print operations where the customer has already done most of the design work and sometimes supplementing this with their own product range to take advantage of repeat business). The main argument in this case (and corroborated by others) is that the WCM paradigm is important though not to hold the measures of effectiveness at face-value for different manufacturing environments. The argument posed by Petroni, Zammori [62] was of a similar nature to Muda and Hendry [61] in that the universalistic and generalised nature of the WCM study by Schonberger [63] was not sufficient (nor practical) in the HVLV context. In this sense, the themes were adopted from Schonberger [63] though the principles within the themes were adapted to suit a HVLV manufacturing environment.

Keeping with this line of thought, there are also numerous studies that seem to suggest that some aspects of HVLV manufacturing operations management are, perhaps, more important than others in ensuring HVLV manufacturing excellence. As an example, some authors take a more pragmatic approach and recognise that, yes, while these practices can be adapted to a certain context, that doesn't necessarily mean they should. That is to say, whilst the impetus remains relatively clear in the improvement of HVLV manufacturing operations and at the same time retaining/gaining competitive advantage, there are some tools which are more effective than others. Hendry [50], for instance, calls these big impact and small impact changes. Big impact changes include improving visibility, exploiting capacity, improving information flow, improving planning and continual improvement efforts whilst small impact changes revolve around engineering and design activities. Despite this, it is interesting to note that improving engineering and design activities seems to be a major focus on HVLV manufacturing research in recent times [64].

Another stream of research associated with the design of ERP systems for HVLV manufacturing environments provides further insight into the rhetoric guiding HVLV manufacturing improvement initiatives. In the generation of a reference model for production planning and control in what they label as "versatile manufacturing" organisations, Persona, Regattieri [26] found, through multi-case research, that customer requirements definition and commercial configuration of customer orders, supply and production planning as well as project evaluation and control mechanisms as key areas for improvement in HVLV environments. Following on from this, Adrodegari, Bacchetti [25] found that different processes were more critical than others in their case research of ETO PPC in an Italian context. They found support processes such as cost control, planning and project management to be critical software functionalities for ERP in a HVLV manufacturing environment. They also found quotation and order management as well as design and commissioning activities to be of comparable criticality. Their process reference framework encompasses the best-practices they deduced in lieu of the operational difficulties HVLV manufacturers were facing in their context. Keeping with this theme, Aslan, Stevenson [65] studied the applicability of ERP systems in a HVLV manufacturing environment. They took customer enquiry management, design and engineering, job entry, job release and dispatching, supply chain and customer relationships to be key defining characteristics of HVLV manufacturing operations - all with a heavy influence on the functionality requirements of ERP software in this context. Their work was further validated in an empirical study later on [66].

In a general sense, the themes surrounding the adoption of HVLV better management practices converge quite well, despite differences associated with the specific aims of research. The key difficulties in achieving greater performance are well understood as the various case-studies have demonstrated - production planning and control, design and engineering, customer and supplier relationships as well as "traditional" project management are all recurring themes (though some appear less often than others). What is also clearly evident is that whilst the general rhetoric would seem to suggest a good understanding of the HVLV manufacturer aims, most studies would also stress the inherent trade-off associated with some of the practices which would appear to boost performance in one area whilst being detrimental in another. Hendry [50] in one of her early studies was fighting with issues associated with repeat business, particular when attempting to build longer-term relationships with suppliers. The issue of repeat business has since seen further investigation [23, 29] which suggests the existence of different types of HVLV manufacturers according to their focus on repeat business and the types of contracts being sought after. Other recommended practices would suggest the adoption of manufacturing cells or similar product grouping activities. Such practices and structural changes can result in considerable improvements in operational efficiency, and it would be considered a "nice to have" in a HVLV manufacturing environment as many would advocate, though, again, this is going against the fundamental underlying logic guiding a HVLV manufacturing strategy. Indeed, the HVLV manufacturing literature appears stalled when it comes to issues associated improving operational efficiency whilst retaining the one thing that makes them what they are - there ability to customise - heavily - project after project.

\section{HVLV MANUFACTURER AMBIDEXTERITY AND BETTER MANAGEMENT PRACTICES - BRIDGING THE GAP}

Earlier, we eluded to the fact that HVLV manufacturing better management practices can help facilitate greater organisational performance through operational excellence. At the same time, we recognised the dynamism and complexity associated with such a manufacturing environment means these management practices must allow for greater flexibility - both in terms of short-term adaptation to changing project requirements amongst a wide variety of customers, as well as 
longer-term strategic flexibility to transform the organisation in lieu of changing market and customer characteristics. In addition to this, and perhaps more importantly in todays' manufacturing climate, the HVLV manufacturer must also be able to pro-actively facilitate change and engage flexibility mechanisms without necessarily relying on an external stimulus. This, of course, brings to light the importance of dynamic capability building through operational routines that help facilitate the three main elements of a dynamic capability - sensing opportunities and threats, seizing these through the mobilisation of resources and continuous transformation (or reconfiguration) [67]. Given the recent reconceptualisation of ambidexterity as a dynamic capability [7,21] and the nested organisational paradoxes that ensue as part of this capability building exercise (long-term vs short-term, efficiency vs flexibility and others in relation to organisational identity and purpose) we base the proceeding discussion on the interactions between ambidextrous HVLV manufacturing organisations and better management practices on the routines-based-view of organisations $[67,68]$ as well as the paradox-based view of organisational tensions [69]. To highlight how ambidexterity is enacted through better management practices in HVLV manufacturing, we base our discussion on a selection of management practices designed to purposefully induce variation towards exploratory means and reduce it in the hopes of achieving operational parity.

The exploratory aspects of better management practices as routinised patterns of behaviour have recently begun to be investigated. Agarwal, Brown [70] for instance found that Australian manufacturers that adopt clusters of what they deem better management practices [based off 40] observe increased innovation capabilities in the form of more innovations produced. Indeed, the idea that various clusters of better management practices can help facilitate innovation is certainly not a new concept. It does, however, hit a road block when "innovation", in the sense of coming up with novel solutions, is the business of the organisation. For HVLV manufacturing, innovation is quite often seen through a process-based lens in the incremental improvement of lead-time through flow and capacity enhancements (the impetus behind production planning and control), though this seems to resemble the exploitation of existing resources. Exploration for HVLV manufacturing would appear to concern the pro-active pursuit of new business opportunities through expanding/changing, and, in effect, repositioning the organisation towards different customer segments whilst at the same time leverage the inherent customisation capabilities. This also has to do with leveraging the uncertainty associated with project-based work. Indeed, there are quite a few ways in which project-based organisations in general can leverage uncertainty [c.f. 71]. For HVLV manufacturers in particular, daily routines concerning process optimisation, customer engagement, contract negotiation and project governance mechanisms can all enhance a HVLV manufacturers' capability to leverage uncertainty towards greater performance [see 72 for a detailed explanation of this]. In this instance, it is possible for the same management practice, initially designed to facilitate greater operational performance, to be used as an exploratory mechanism for longer-term competitive advantage. The trick, however, comes in how these ambidextrous capabilities are enacted through the use of these better management practices. Here, the issue is more concerning the interaction of these tools with the broader management-model of the manufacturer, and in-turn, its interaction with the overall business logic guiding capability investment decisions.

One of the foundational elements for achieving ambidexterity, appears to be the knowledge of when to engage, modify or remove management practices and, of course, how. Underpinning this view is that better management practices need not necessarily be enacted as essentially codified artifacts - something like Standard Operating Procedures. Routines, in a general sense, are said to be composed of both an ostensive and performative aspect [73]. They are also recognisable in the observed sequence of actions as they are bound by interdependencies - if one action follows (or is dependent on another). On the other hand, a routine is repetitive in the observed outcomes of a sequence of actions in lieu of an external stimulus - if a certain pattern of actions is observed based on a particular stimulus, it is reasonable to assume a similar pattern will occur in response to a similar stimulus whereby a stimulus could be actor related or from the external environment (another routine, for instance)[74]. In other words, for a routine to be repetitive, the recognisable patterns must be the same every time. A key learning from this conceptualisation is the nature of actions and the role agency plays in these interactions between (and among) individuals management practices and structures $[73,75]$. In this instance, routines can also merge with each other to form new routines some more flexible than others. There is also a commonly held belief that routines exist in a hierarchy where one routine (or set of routines) can be used to influence other lower-level routines [76]. This phenomenon can be said to underpin the existence of ambidextrous capabilities [21, 77].

Taking on this view, it becomes quite evident that the transformative aspects of better management practices that exists in their simultaneous role as providers of stability and a force for change depends as much on their interaction with other management practices as they do with the HVLV manufacturing environment in general. For instance, production planning and control (PPC) management practices concern the effective execution of all front-end activities in the manufacturing value chain, including the likes of delivery date setting, customer enquiries management as well as achieving flow and capacity optimisation. It is quite well established that certain PPC methodologies are more effective in a HVLV manufacturing environment than others [78] and when implemented can lead to significant gains in output productivity [79]. The exploratory component is realised in the reduced instances of management by fire-fighting, particularly when it comes to peak business periods [80]. Here, it is claimed that key decision makers would have made available more mental capacity to undertake strategic longer-term thinking. Though such a capability also requires effective quality management, procurement strategies and sales and estimation routines in order to remain viable. In this instance, it is also critical to observe that such a cocktail of management practices (often labelled as clusters) may not be complimentary as some routines that underpin quality management, for instance, may not yield the necessary flexibility required to 
make effective resource adjustments in the case of production planning and control. This takes us back to the idea that variation, selection and retention of routines are also enacted in situational practice [74] - they appear rigid in their guise as processes though can observe change in the socio-material interactions between different actions [73]. That is to say, the people involved in actually undertaking the work would implement the various routines in the process of PPC and quality management that are complimentary at that time - even if they do seem to be intuitively at odds with each other. In this instance, one can claim that ambidextrous HVLV manufacturers would be adopting clusters of better management practices that can help the organisation to explore, exploit and transform as necessary.

\section{CONCLUSIONS}

This paper presented a work-in-progress that aims to shed some light on how organisations actually operationalise ambidexterity. More specifically, we focussed our discussion on the role "better" management practices play in realising ambidexterity in a unique organisational context known as high-variety, low-volume (HVLV) manufacturing. In this instance, we drew on the routines-based view of organisations as well as the paradox-based view of organisational tensions to conceptually demonstrate the exploratory, exploitative and transformative qualities of "better" management practices as they impact, and are impacted by, ambidextrous capabilities. From this theory-building exercise we contribute to ambidexterity literature by providing a more nuanced perspective on the role routinised patterns of behaviour can play in facilitating an organisations' ambidextrous capabilities. We also break-free from the more efficiency driven research paradigm in HVLV manufacturing literature by highlighting the significance of ambidextrous capabilities in such a context as well as the dual role of "better" management practices in achieving this. Given the conceptual nature of this paper and its classification as a work-in-progress, further work is required to empirically validate the arguments made in this paper towards a more comprehensive understanding of the underlying "mechanisms" of ambidextrous capabilities in HVLV manufacturing.

\section{REFERENCES}

1. O'Reilly, C.A. and M.L. Tushman, Organizational ambidexterity: Past, present, and future. The Academy of Management Perspectives, 2013. 27(4): p. 324-338.

2. Junni, P., et al., Organizational ambidexterity and performance: A meta-analysis. The Academy of Management Perspectives, 2013. 27(4): p. 299-312.

3. Turner, N., J. Swart, and H. Maylor, Mechanisms for managing ambidexterity: A review and research agenda. International Journal of Management Reviews, 2013. 15(3): p. 317-332.

4. Patel, P.C., S. Terjesen, and D. Li, Enhancing effects of manufacturing flexibility through operational absorptive capacity and operational ambidexterity.
Journal of Operations Management, 2012. 30(3): p. 201-220.

5. Kortmann, S., et al., Linking strategic flexibility and operational efficiency: The mediating role of ambidextrous operational capabilities. Journal of Operations Management, 2014. 32(7): p. 475-490.

6. Adler, P.S., et al., Perspectives on the productivity dilemma. 2009. 27(2): p. 99-113.

7. O'Reilly, C.A. and M.L. Tushman, Ambidexterity as a dynamic capability: Resolving the innovator's dilemma. Research in organizational behavior, 2008. 28: p. 185-206.

8. Eisenhardt, K.M., N.R. Furr, and C.B. Bingham, CROSSROADS-Microfoundations of performance: Balancing efficiency and flexibility in dynamic environments. Organization science, 2010. 21(6): p. 1263-1273.

9. Lavie, D., U. Stettner, and M.L. Tushman, Exploration and exploitation within and across organizations. Academy of Management annals, 2010. 4(1): p. 109-155.

10. March, J.G., Exploration and exploitation in organizational learning. Organization science, 1991. 2(1): p. 71-87.

11. Gibson, C.B. and J. Birkinshaw, The antecedents, consequences, and mediating role of organizational ambidexterity. Academy of management Journal, 2004. 47(2): p. 209-226.

12. Gupta, A.K., K.G. Smith, and C.E. Shalley, The interplay between exploration and exploitation. Academy of management journal, 2006. 49(4): p. 693-706.

13. Schreyögg, G. and J. Sydow, CROSSROADSOrganizing for fluidity? Dilemmas of new organizational forms. Organization Science, 2010. 21(6): p. 1251-1262.

14. Birkinshaw, J. and K. Gupta, Clarifying the distinctive contribution of ambidexterity to the field of organization studies. The Academy of Management Perspectives, 2013. 27(4): p. 287-298.

15. D'Souza, D.E., P. Sigdyal, and E. Struckell, Relative ambidexterity: a measure and a versatile framework. The Academy of Management Perspectives, 2017. 31(2): p. 124-136.

16. Matthews, R.L., K.H. Tan, and P.E.J.J.o.M.T.M. Marzec, Organisational ambidexterity within process improvement: An exploratory study of four projectoriented firms. 2015. 26(4): p. 458-476.

17. Tamayo-Torres, J., et al., Ambidexterity, performance and environmental dynamism. International Journal of Operations \& Production Management, 2017. 37(3): p. 282-299.

18. Frank, H., et al., Environmental dynamism, hostility, and dynamic capabilities in medium-sized enterprises. 2017. 18(3): p. 185-194.

19. Herzallah, A., et al., Quality ambidexterity, competitive strategies, and financial performance: 
An empirical study in industrial firms. 2017. 37(10): p. 1496-1519.

20. Wu, S.J., S.A. Melnyk, and B.B.J.D.S. Flynn, Operational capabilities: The secret ingredient. 2010. 41(4): p. 721-754.

21. Wilden, R., et al., Revisiting James March (1991): Whither exploration and exploitation? 2018: $\mathrm{p}$. 1476127018765031.

22. Benner, M.J. and M.L.J.A.o.m.r. Tushman, Reflections on the 2013 Decade Award"Exploitation, exploration, and process management: The productivity dilemma revisited" ten years later. 2015. 40(4): p. 497-514.

23. Amaro, G., L. Hendry, and B. Kingsman, Competitive advantage, customisation and a new taxonomy for non make-to-stock companies. International Journal of Operations \& Production Management, 1999. 19(4): p. 349-371.

24. Portioli-Staudacher, A. and M. Tantardini, Lean implementation in non-repetitive companies: a survey and analysis. International Journal of Services and Operations Management, 2012. 11(4): p. 385406.

25. Adrodegari, F., et al., Engineer-to-order (ETO) production planning and control: an empirical framework for machinery-building companies. Production Planning \& Control, 2015(ahead-ofprint): p. 1-23.

26. Persona, A., A. Regattieri, and P. Romano, $A n$ integrated reference model for production planning and control in SMEs. Journal of Manufacturing Technology Management, 2004. 15(7): p. 626-640.

27. Little, D., et al., Integrated planning and scheduling in the engineer-to-order sector. International Journal of Computer Integrated Manufacturing, 2000. 13(6): p. 545-554.

28. Hill, T., Manufacturing Strategy: Text and Cases. 2000: Irwin/McGraw-Hill.

29. Hendry, L.C., Product customisation: an empirical study of competitive advantage and repeat business. International Journal of Production Research, 2010. 48(13): p. 3845-3865.

30. Kingsman, B., et al., Responding to customer enquiries in make-to-order companies: problems and solutions. Production, 1996. 6(2): p. 195-207.

31. Ashforth, B.E. and F.A. Mael, Oranizational Identity and Strategy as a Context for the Individual. Advances in strategic management, 1996. 13: p. 1964.

32. Gioia, D.A., et al., Organizational identity formation and change. Academy of Management Annals, 2013. 7(1): p. 123-193.

33. Gosling, J. and M.M. Naim, Engineer-to-order supply chain management: A literature review and research agenda. International Journal of Production Economics, 2009. 122(2): p. 741-754.
34. Salvador, F., et al., Mix flexibility and volume flexibility in a build-to-order environment: synergies and trade-offs. International Journal of Operations \& Production Management, 2007. 27(11): p. 11731191.

35. Kingsman, B.G., Input/output backlog control and dynamic capacity planning in Versatile Manufacturing companies, in Stochastic Modelling in Innovative Manufacturing, A.H. Christer, S. Osaki, and L.C. Thomas, Editors. 1997. p. 97-122.

36. Hendry, L., B. Kingsman, and P. Cheung, The effect of workload control (WLC) on performance in maketo-order companies. Journal of Operations Management, 1998. 16(1): p. 63-75.

37. Kingsman, B., et al., Integrating marketing and production planning in make-to-order companies. International Journal of Production Economics, 1993. 30: p. 53-66.

38. Zorzini, M., M. Stevenson, and L.C. Hendry, Customer Enquiry Management in global supply chains: A comparative multi-case study analysis. European Management Journal, 2012. 30(2): p. 121140.

39. Bloom, N., et al., Management practices across firms and countries. The Academy of Management Perspectives, 2012. 26(1): p. 12-33.

40. Bloom, N. and J. Van Reenen, Measuring and explaining management practices across firms and countries. 2006, National Bureau of Economic Research.

41. Agarwal, R., et al., Global comparison of management practices, in Handbook of Research on Managing Managers. 2015, Edward Elgar Publishing: Cheltenham, UK.

42. Bloom, N. and J. Van Reenen, Why do management practices differ across firms and countries? The Journal of Economic Perspectives, 2010. 24(1): p. 203-224.

43. Agarwal, R., et al., Managerial Practices in a High Cost Manufacturing Environment: A Comparison with Australia and New Zealand. 2014.

44. Bromiley, P. and D. Rau, Towards a practice-based view of strategy. Strategic Management Journal, 2014. 35(8): p. 1249-1256.

45. Bromiley, P. and D. Rau, Operations management and the resource based view: Another view. Journal of Operations Management, 2016. 41: p. 95-106.

46. Voss, C.A., Alternative paradigms for manufacturing strategy. International Journal of Operations \& Production Management, 1995. 15(4): p. 5-16.

47. Sousa, R. and C.A. Voss, Contingency research in operations management practices. Journal of Operations Management, 2008. 26(6): p. 697-713.

48. Skinner, W., The focused factory. 1974.

49. Slomp, J., J.A. Bokhorst, and R. Germs, A lean production control system for high-variety/lowvolume environments: a case study implementation. 
Production Planning and Control, 2009. 20(7): p. 586-595.

50. Hendry, L.C., Applying world class manufacturing to make-to-order companies: problems and solutions. International Journal of Operations \& Production Management, 1998. 18(11): p. 1086-1100.

51. Mi Dahlgaard-Park, S., et al., Similarities and differences between TQM, six sigma and lean. The TQM magazine, 2006. 18(3): p. 282-296.

52. Abrahamson, E. and G. Fairchild, Management fashion: Lifecycles, triggers, and collective learning processes. Administrative science quarterly, 1999. 44(4): p. 708-740.

53. Alexopoulos, M. and T. Tombe, Management matters. Journal of Monetary Economics, 2012. 59(3): p. 269-285.

54. Gibson, J.W. and D.V. Tesone, Management fads: Emergence, evolution, and implications for managers. The Academy of Management Executive, 2001. 15(4): p. 122-133.

55. Bloom, N., R. Sadun, and J. Van Reenen, Management as a Technology? 2016, National Bureau of Economic Research.

56. Womack, J.P., D.T. Jones, and D. Roos, Machine that changed the world. 1990: Simon and Schuster.

57. Schonberger, R., World Class Manufacturing Casebook: Implementing JIT and TQC. 1987: Free Press.

58. Birkie, S.E. and P. Trucco, Understanding dynamism and complexity factors in engineer-to-order and their influence on lean implementation strategy.

Production Planning \& Control, 2016. 27(5): p. 345359.

59. Fox, S., et al., Formulation of robust strategies for project manufacturing business. International Journal of Managing Projects in Business, 2009. 2(2): p. 217237.

60. Mello, M.H., J.O. Strandhagen, and E. Alfnes, Analyzing the factors affecting coordination in engineer-to-order supply chain. International Journal of Operations \& Production Management, 2015. 35(7): p. 1005-1031.

61. Muda, M.S. and L. Hendry, The SHEN model for MTO SMEs - A performance improvement tool. International Journal of Operations \& Production Management, 2003. 23(5-6): p. 470-486.

62. Petroni, A., F. Zammori, and G. Marolla, World class manufacturing in make-to-order batch-production SMEs: an exploratory analysis in northern Italy. International Journal of Business Excellence, 2017. 11(2): p. 241-275.

63. Schonberger, R., World class manufacturing: the next decade: building power, strength, and value. 1996.

64. Cannas, V.G., et al., Insights from the empirical applications of the customer order decoupling point, in European Operations Management Association Conference. 2018: Budapest.

65. Aslan, B., M. Stevenson, and L.C. Hendry, Enterprise resource planning systems: An assessment of applicability to make-to-order companies. Computers in Industry, 2012. 63(7): p. 692-705.

66. Aslan, B., M. Stevenson, and L.C. Hendry, The applicability and impact of Enterprise Resource Planning (ERP) systems: Results from a mixed method study on Make-To-Order (MTO) companies. Computers in Industry, 2015. 70: p. 127-143.

67. Teece, D.J., A capability theory of the firm: an economics and (strategic) management perspective. 2017: p. 1-43.

68. Ketokivi, M. and R. Schroeder, Manufacturing practices, strategic fit and performance: a routinebased view. International Journal of Operations \& Production Management, 2004. 24(2): p. 171-191.

69. Lewis, M.W. and W.K. Smith, Paradox as a metatheoretical perspective: Sharpening the focus and widening the scope. The Journal of Applied Behavioral Science, 2014. 50(2): p. 127-149.

70. Agarwal, R., et al., Management practices of Australian manufacturing firms: why are some firms more innovative? International Journal of Production Research, 2014. 52(21): p. 6496-6517.

71. Saunders, F.C., A.W. Gale, and A.H. Sherry, Conceptualising uncertainty in safety-critical projects: A practitioner perspective. International Journal of Project Management, 2015. 33(2): p. 467478.

72. Katic, M. and R. Agarwal, The Flexibility Paradox: Achieving Ambidexterity in High-Variety, LowVolume Manufacturing. Global Journal of Flexible Systems Management, 2018: p. 1-18.

73. Feldman, M.S. and B.T.J.A.s.q. Pentland, Reconceptualizing organizational routines as a source of flexibility and change. 2003. 48(1): p. 94118.

74. Pentland, B.T., et al., Dynamics of organizational routines: A generative model. 2012. 49(8): p. 14841508.

75. Felin, T., et al., Microfoundations of routines and capabilities: Individuals, processes, and structure. 2012. 49(8): p. 1351-1374.

76. Helfat, C.E. and S.G. Winter, Untangling dynamic and operational capabilities: Strategy for the $(N)$ ever-changing world. Strategic management journal, 2011. 32(11): p. 1243-1250.

77. Wilden, R., T.M. Devinney, and G.R.J.T.A.o.M.A. Dowling, The architecture of dynamic capability research identifying the building blocks of a configurational approach. 2016. 10(1): p. 997-1076.

78. Stevenson, M., L.C. Hendry, and B. Kingsman, A review of production planning and control: the applicability of key concepts to the make-to-order 
industry. International journal of production research, 2005. 43(5): p. 869-898.

79. Silva, C., M. Stevenson, and M. Thurer, A case study of the successful implementation of workload control: a practitioner-led approach. Journal of

Manufacturing Technology Management, 2015. 26(2): p. 280-296.

80. Stevenson, M. and M. Vanharanta, The effects of managerial decision making behaviour and order book size on workload control system implementation in Make-To-Order companies. Production Planning \& Control, 2015. 26(2): p. 97-115. 